\title{
Identification of SENP1 inhibitors through in silico screening and rational drug design
}

Yaxue Zhao, ${ }^{\mathrm{a}}$ Zhongli Wang, ${ }^{\mathrm{a}}$ Jianchen Zhang, ${ }^{\mathrm{a}}$ Huchen Zhou, ${ }^{\mathrm{a}, *}$

${ }^{a}$ State Key Laboratory of Microbial Metabolism, School of Pharmacy, Shanghai Jiao Tong

University, Shanghai 200240, People's Republic of China

"Corresponding author. E-mail addresses: hczhou@sjtu.edu.cn; Tel.: +86 2134206721.

\section{Abstract}

The small ubiquitin-related modifier (SUMO)-specific proteases (SENPs) catalyze the deconjugation of SUMO from their substrate proteins. SENP1 which is the most studied isoform is closely related to many cancers such as prostate cancer and colon cancer, thus representing a potential therapeutic target for cancer treatment. In the present study, we identified eleven SENP1 inhibitors representing a variety of scaffolds through in silico screening. Based on these scaffolds, a series of new compounds were designed and synthesized in order to improve their SENP1 inhibitory potency. As a result, compounds with $\mathrm{IC}_{50}$ as

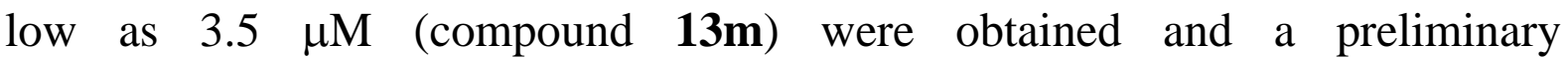
structure-activity relationship was discussed.

Keywords: SENP1 inhibitor, in silico screening, rational design, cancer

Abbreviations: SUMO, small ubiquitin-related modifier; SENP, SUMO-specific protease; pre-SUMO, SUMO precursor; E1, SUMO-activating enzyme; E2, SUMO-conjugation enzyme; E3, SUMO protein ligase; VEGF, 
vascular endothelial growth factor; HIF1, hypoxia-inducible factor 1; HTVS, high-throughput virtual screening; SP, standard precision; XP, extra precision.

\section{Introduction}

Small ubiquitin-like modifier (SUMO) is a member of the ubiquitin-like protein family that modulates cellular functions of a variety of target proteins [1-3]. Sumoylation has emerged as an important protein post-translational modification that can participate in transcriptional regulation, nuclear transport, maintenance of genome integrity, and signal transduction in human $[4,5]$. Dysfunction of sumoylation is associated with a broad range of diseases including cancer, neurodegenerative syndrome, diabetes, viral infection, and development defects [6]. As a reversible process, sumoylation is mediated by SUMO-activating enzyme (E1), SUMO-conjugation enzyme (E2) and SUMO protein ligase (E3), and is readily reversed by a family of SUMO-specific proteases (SENPs) [7]. SENPs, a family of cysteine proteases are responsible for the deconjugation of SUMO from substrate proteins [8]. Six isoforms of SENPs (SENP1, 2, 3, 5, 6, and 7) from human have been identified and 
characterized, each of them has a distinct subcellular localization and substrate specificity $[9,10]$. Among them, SENP1 has been shown to be overexpressed in more than $50 \%$ of prostate cancer, and the critical role of SENP1 in tumorigenesis has been demonstrated in transgenic mice [11-13]. Furthermore, it has been found that SENP1 is essential for colon cancer cell growth [14], and enhances vascular endothelial growth factor (VEGF) production by regulating the stability of hypoxia-inducible factor-1 (HIF-1) $[15,16]$. Thus, SENP1 may serve as an attractive target for developing new cancer therapeutics.

Since 2011, several SENP1 inhibitors have been reported by our and other groups [17-20], including the benzodiazepine-based peptidomimetic covalent inhibitors from our group [17], the SUMO-derived peptide-based covalent inhibitors from Bogyo's group [18], the 2-(4-chlorophenyl)-2-oxoethyl 4-benzamidobenzoates and 1-[4-(N-benzylamino)phenyl]-3-phenylureas as non-covalent inhibitors from Zhang [19] and Chen's [20] groups, respectively. These inhibitors showed moderate inhibitory activity which needs major improvement in order to be useful for in-depth in vivo studies. At the same time, the availability of a variety of scaffolds would also facilitate the discovery of potent inhibitors, and eventually lead to the development of therapeutic agents for SENP1-related pathological conditions and chemical probes to further the understanding of the biological functions of SENP1.

In this study, we identified a number of new scaffolds as SENP1 inhibitors through in silico screening. Two of the scaffolds were analyzed and a hybrid 
structure based on these two scaffolds was designed and optimized by structure-based rational design. Thus, a series of new SENP1 inhibitors were developed and an $\mathrm{IC}_{50}$ value as low as $3.5 \mu \mathrm{M}$ (compound $\mathbf{1 3 m}$ ) was achieved. This work demonstrated that in silico screening followed with rational design is an effective strategy for the discovery of inhibitors against novel targets such as SENP1. It also provided new lead compounds for further development of SENP1 inhibitors as potential therapeutic agents and functional probes.

\section{Results and discussion}

\subsection{Inhibitor identification via in silico screening}

The SENP1 protein undergoes significant conformational change upon substrate protein binding and a binding tunnel capped by residues Trp465 and Val532 is induced. Thus, the co-crystal structure of SENP1 and pre-SUMO [21] (PDB ID: 2IY1) was used as the starting structure for in silico screening as it represents the binding conformation of SENP1 with the presence of the binding tunnel. (Figure 1A)

The catalytic triad, Cys603, His533, and Asp550, of SENP1 is critical for its catalytic activity, the corresponding mutants (C603A, H533A, and D550A) are completely inactive in the deconjugation of SUMO [22]. The binding tunnel of SENP1, which is composed of amino acids Trp465, His529, Val532, Trp534, and Leu466, is essential for interactions with the C-terminal of SUMO for the subsequent deconjugation of SUMO from modified proteins. The catalytic activity of SENP1 is seriously impaired or completely abolished in the 
corresponding mutants including W465A, H529A, and W534A [22]. Thus, these key residues, Trp465, Leu466, His529, Val532, His533, Trp534 and Cys603, are all included in the docking box (Figure 1A) for virtual screening. The centroid of $\mathrm{T}^{90} \mathrm{GGH}^{93}$ peptide (red in Figure 1A) located inside the binding tunnel is used to generate the docking grid.

As shown in Figure 1B, the compounds from Specs database were prepared by LigPrep and screened by Glide in three consecutive modes: high-throughput virtual screening (HTVS), standard precision (SP), and extra precision (XP). The top ranked 150 molecules from SP screening and the top ranked 150 molecules from XP screening were submitted to manual inspection using the following criteria: binding pose should closely resemble that of pre-SUMO, at least four hydrogen bonds should be formed, and scaffold diversity should be considered. Finally, 30 compounds were selected and purchased for SENP1 inhibitory assay.

We showed that 11 of the 30 selected compounds showed SENP1 inhibitory activities with $\mathrm{IC}_{50}$ below $50 \mu \mathrm{M}$ (Table 1). These inhibitors represent a diversity of scaffolds, providing hits for further optimization and development.

\subsection{Representative structures of SENP1 inhibitors}

Among the identified SENP1 inhibitors with $\mathrm{IC}_{50}$ values below $20 \mu \mathrm{M}$, the structures of compounds $\mathbf{1}, \mathbf{5}, \mathbf{7}$ and $\mathbf{9}$ can be summarized into a representative structure, $A^{1}-L^{1}-A^{2}-L^{2}-A^{3}$, as shown in Figure $2 A$. In the docked poses, the $A^{1}$ moiety points to either the Phe496-His529 site or the 
Lys455-Thr459-Asn467-Asp468 site. The $\mathrm{L}^{1}-\mathrm{A}^{2}-\mathrm{L}^{2}$ moiety is inserted into the binding tunnel and covered by residues Trp465, Leu466, His529, Val532, Trp534, Gln597, and Cys603. The $\mathrm{A}^{2}$ moiety has conserved interaction with Trp465 and/or Trp534, while the $\mathrm{L}^{1}$ and $\mathrm{L}^{2}$ linkages form hydrogen bond interactions. The $\mathrm{A}^{3}$ moiety points to the His533-Met552 site.

The predicted binding poses of compounds $\mathbf{1}$ and $\mathbf{5}$ are shown in Figure 2. Both compounds assume binding poses that closely resemble the binding conformation of peptide $\mathrm{E}^{88} \mathrm{QTGGHS}^{94}$ derived from pre-SUMO. Compound $\mathbf{1}$ showed hydrogen bonds with Lys455, His529, Val532, Leu466, and Gln597, $\pi-\pi$ interaction with Trp465, His533, and Trp534, and hydrophobic interaction with Met552. Compound 5 showed hydrogen bonds with Leu466, His529, Va1532, and Gln597, $\pi-\pi$ interaction with Trp465, His529, His533, and Trp534, and hydrophobic interaction with Phe496 and Met552.

\subsection{Structural optimization and structure-activity relationship (SAR) study}

In order to improve their SENP1 inhibitory activity, we designed and synthesized compounds 13a-13n based on the core structural features of $A^{1}-L^{1}-A^{2}-L^{2}-A^{3}$ which is derived from the initial hits.

We selected compounds $\mathbf{1}$ and $\mathbf{5}$ as the model compounds. Their aryl groups, phenyl and benzothiophenyl, were incorporated as the $\mathrm{A}^{1}, \mathrm{~A}^{2}$, and $\mathrm{A}^{3}$ groups. Their amide groups with the nitrogen atom either directly connected to or a carbon atom away from the central phenyl were incorporated as the $\mathrm{L}^{1}$ and $\mathrm{L}^{2}$ linkage groups. This resulted in the structure of compound 13a whose SENP1 
inhibitory activity $\left(\mathrm{IC}_{50}=26.6 \mu \mathrm{M}\right)$ was shown to be weaker than compounds $\mathbf{1}$ and 5. The docking structure of 13a with SENP1 showed that the structure spans a shorter dimension than compound $\mathbf{1}$ or $\mathbf{5}$, which might contribute to its decreased activity. After the benzothiophenyl was replaced by a larger group, i.e. bromobiphenyl, the inhibitory activity (compound $\mathbf{1 3 b}, \mathrm{IC}_{50}=9.1 \mu \mathrm{M}$ ) became superior to compounds $\mathbf{1}$ and $\mathbf{5}$. The docking structure of 13b in SENP1 showed that the phenyl group at the $\mathrm{A}^{3}$ terminus was near the His533 and Met552 residues which potentially could form sandwiched hydrophobic interaction, and extension of the linkage group may enhance this interaction (Figure 3). Thus, compound 13c with an extended linkage group containing a double bond was synthesized and showed a slightly improved $\mathrm{IC}_{50}$ value of $6.4 \mu \mathrm{M}$. The docked model showed that compound 13c formed favorable hydrophobic interaction with His533 and Met552. Both compounds 13b and 13c formed four hydrogen bonds with residues Leu466, His529, Val532, and Gln597.

Next, compounds $\mathbf{1 3 d} \mathbf{d}-\mathbf{1 3} \mathbf{j}$ with various substituents at the $A^{1}$ terminus were synthesized in order to further improve the SENP1 inhibitory activity from compound 13c. The meta-bromo derivative $13 d$ showed a 2.5 -fold decrease of activity $\left(\mathrm{IC}_{50}=16.4 \mu \mathrm{M}\right)$. Removal of the bromo- atom gave comparable activity $\left(\mathbf{1 3 e}, \mathrm{IC}_{50}=9.2 \mu \mathrm{M}\right)$. The para-methoxy compound $\mathbf{1 3 f}$ showed the best potency $\left(\mathrm{IC}_{50}=4.9 \mu \mathrm{M}\right)$ among the derivatives of 13c. When the biphenyl

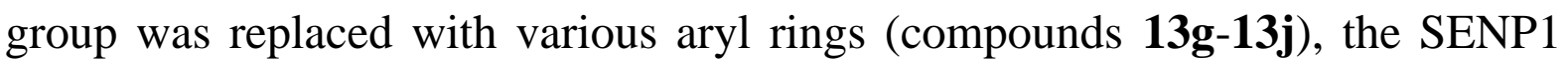
inhibitory activity was not improved. 
We next tested the effect of the flexibility of linkage group $\mathrm{L}^{2}$ on the inhibitory activity. Compounds 13k-13n which are the single bond derivatives of the double bond-containing compounds 13c, 13e, 13f, and 13g were synthesized. For compounds $\mathbf{1 3 k}$, 13l, and 13n, more flexibility led to either reduced or comparable activity. However, compound $\mathbf{1 3 m}$ gave the most potent inhibitory activity $\left(\mathrm{IC}_{50}=3.5 \mu \mathrm{M}\right)$ among all compounds in this work.

The synthesis of these compounds are described below. As shown in Scheme 1, aminomethylaniline was used as the common starting material. After the benzyl amino group was protected by Boc, the phenylamino group was coupled with various carboxylic acids in the presence of EDCI/DMAP followed by treatment with TFA to give compounds $12 \mathbf{a}-12 \mathrm{c}$. Compounds 13a-13n were subsequently prepared by coupling compounds $12 \mathbf{a}-\mathbf{1 2 c}$ with the corresponding carboxylic acids.

\section{Conclusions}

The SENPs which catalyze the deconjugation of SUMO from their target proteins play essential roles in a variety of critical cellular events. Dysfunction of the equilibrium of SUMOylation and deSUMOylation is associated with numerous pathological conditions including cancer. Specifically, SENP1 has been found to be closely related to the prostate and colon cancer. As a potential therapeutic target, the discovery of SENP1 inhibitors remains in its infancy. In this study, we identified 11 SENP1 inhibitors with various scaffolds through in 
silico screening. Based on the structural features and the docked poses of the initial hits, compounds 13a-13n were designed and synthesized, which gave improved SENP1 inhibitory activity with compound $13 \mathrm{~m}\left(\mathrm{IC}_{50}=3.5 \mu \mathrm{M}\right)$ as the most potent compound in this series. We believe these new SENP1 inhibitors will contribute to the further development of SENP1 inhibitors as potential therapeutics and functional probes.

\section{Material and methods}

4.1. Preparation of protein and small molecule database for computational study

The 3D structure of the SENP1-pre-SUMO complex (PDB ID: 2IY1) was used to derive the SENP1-T ${ }^{90} \mathrm{GGH}^{93}$ peptide complex that was used in the study and is described as follows. Using the workflows of Maestro [23], the A603 was mutated back to $\mathrm{C} 603$, the hydrogen atoms were added, the bond orders were assigned, the added hydrogen atoms were optimized with exhaustive sampling method, and all atoms were energy minimized to reach the convergent RMSD of $0.30 \AA$ with the OPLS_2005 force field [24]. The docking grid was then generated using Glide 5 [25]. The centroid of the $\mathrm{T}^{90} \mathrm{GGH}^{93}$ peptide was defined as the active site center and the bounding box which contains the acceptable positions for the ligand center was set to $14 \AA \times 14 \AA \times 14 \AA$. The Specs database which includes approximately 197,000 commercially available compounds was used for in silico screening. LigPrep [26] was used to prepare these compounds in OPLS_2005 force field. The possible ionization state at pH 
$=7.0 \pm 2.0$ was generated for each compound. About 350,000 small molecule conformations were generated.

\subsection{In silico screening}

The Glide module [25] was employed to screen the Specs database in order to identify SENP1 inhibitors. The screening was done by three consecutive flows: HTVS (350,000 compounds screened), SP (top ranked 40,000 compounds from HTVS screened), and XP (top ranked 5,000 compoumds from SP screened). The ligands were set to be flexible, the ring conformations were sampled, and the non-planar conformations for amide bonds were penalized. The docked conformations were ranked by Glide scoring function. Both top ranked 150 molecules after SP sieve and top ranked 150 molecules after XP sieve were manually analyzed. Finally, 30 compounds were purchased and tested.

\subsection{Bioactivity assay}

The pET28a-SENP1 plasmid (catalytic core, residues 419-644) was transformed into E. coli BL21 (DE3). Expression of SENP1 was induced with $0.5 \mathrm{mM}$ IPTG at $16{ }^{\circ} \mathrm{C}$ for $16 \mathrm{~h}$. Cell pellets were resuspended in lysis buffer $\left(50 \mathrm{mM} \mathrm{Na} 2 \mathrm{HPO}_{4} / \mathrm{NaH}_{2} \mathrm{PO}_{4} \mathrm{pH} 7.4,300 \mathrm{mM} \mathrm{NaCl}, 10 \%\right.$ glycerol, $10 \mathrm{mM}$ $\beta$-mercaptoethanol, and $10 \mathrm{mM}$ imidazole) and sonicated. SENP1 was purified using Ni-NTA resin (Qiagen) and eluted with elution buffer containing $150 \mathrm{mM}$

imidazole. The pET28a-RanGAP (residues 403-585) and 
pSAE1/SAE2-UBC9-SUMO plasmids were cotransformed into E. coli BL21 (DE3), and similar methods were used in the expression and purification of fusion protein RanGAP-SUMO.

The SENP1 inhibitory effect of the compounds was tested using deSUMOylation assay. SENP1 (4 nM) was incubated with compounds at $37^{\circ} \mathrm{C}$ for $10 \mathrm{~min}$ in reaction buffer $(50 \mathrm{mM}$ Tris- $\mathrm{HCl} \mathrm{pH} \mathrm{8.0,} 20 \mathrm{mM} \mathrm{NaCl}, 2 \mathrm{mM}$ DTT, $2 \mathrm{mM} \mathrm{CaCl} 2)$. Then $5 \mu \mathrm{L}$ RanGAP-SUMO $(2 \mu \mathrm{g} / \mu \mathrm{L})$ was added and incubated for another $25 \mathrm{~min}$ at $37^{\circ} \mathrm{C}$. The reaction was terminated by adding loading buffer and boiling for $5 \mathrm{~min}$. The protein samples were subjected to SDS-PAGE and coomassie staining. The RanGAP-SUMO bands were quantified on the Odyssey infrared scanner $\left(\lambda_{\mathrm{ex}}=680 \mathrm{~nm}\right.$ and $\left.\lambda_{\mathrm{em}}=720 \mathrm{~nm}\right)$.

Percentage inhibition was calculated using the following equation: \%inhibition $=\left[\left(\mathrm{RFU}_{\text {sample }}-\mathrm{RFU}_{\text {blank }}\right) /\left(\mathrm{RFU}_{\text {substrate }}-\mathrm{RFU}_{\text {blank }}\right)\right] \quad \mathrm{x} \quad 100 \%$, sample $\quad-$ RanGAP-SUMO, SENP1, and compounds in assay buffer, blank RanGAP-SUMO, SENP1 in assay buffer, substrate - RanGAP-SUMO in assay buffer without SENP1. For $\mathrm{IC}_{50}$ measurement, a test compound at interval concentrations $(50,25,12.5,6.25,3.12,1.56,0.78,0.39 \mu \mathrm{M})$ was used and the data were fitted with GraphPad to give the $\mathrm{IC}_{50}$ value.

\subsection{Chemistry}

All solvents and reagents were purchased from commercial sources and used without further purification unless otherwise noted. NMR spectra were recorded 
on Bruker Avance III $400 \mathrm{MHz}$ or $600 \mathrm{MHz}$. Chemical shifts are expressed in parts per million (ppm) relative to residual solvent as an internal reference (DMSO- $d_{6}: 2.50$ ). High resolution mass spectra were obtained on Agilent 6530 Accurate Mass Q-TOF LC-MS. Column chromatography was performed using Huanghai silica gel $(45-75 \mu \mathrm{m})$. HPLC analysis was performed on an Agilent 200 with a flow rate of $1 \mathrm{~mL} / \mathrm{min}$ and a gradient of $10 \% \mathrm{v} / \mathrm{v} \mathrm{MeOH}$ in $\mathrm{H}_{2} \mathrm{O}(\mathrm{t}=$ $0 \mathrm{~min})$ to $100 \% \mathrm{MeOH}(\mathrm{t}=15.0 \mathrm{~min})$ stopping at 20 or $25 \mathrm{~min}$ using a $\mathrm{DAD}$ detector. An Agilent Eclipse XDB-C18 column $(4.6 \mathrm{~mm} \times 150 \mathrm{~mm}, 5 \mu \mathrm{m})$ was used. Purity was based on the integrated UV chromatogram (254 nm). The purity of all biological assay compounds was $>95 \%$.

\subsubsection{N-[3-(Aminomethyl)phenyl]benzamide (12a)}

The solution of EDCI $(3.14 \mathrm{~g}, 16.38 \mathrm{mmol})$ and DMAP $(100 \mathrm{mg}, 0.82 \mathrm{mmol})$ in $10 \mathrm{~mL}$ DCM was added dropwise to a mixture of tert-butyl-3-aminobenzyl-carbamate $(2.0 \mathrm{~g}, 9.01 \mathrm{mmol})$ and benzoic acid $(1.0 \mathrm{~g}$, $8.19 \mathrm{mmol}$ ) in $20 \mathrm{~mL} \mathrm{DCM}$ at $0{ }^{\circ} \mathrm{C}$ under nitrogen atmosphere, and the mixture was warmed to r.t. and stirred overnight. After quenched with water and extracted with DCM, the organic layer was washed with $1 \mathrm{M} \mathrm{NaOH}(20 \mathrm{~mL}), 1$ $\mathrm{M} \mathrm{HCl}(20 \mathrm{~mL})$, and saturated $\mathrm{NaHCO}_{3}(10 \mathrm{~mL})$, dried over $\mathrm{Na}_{2} \mathrm{SO}_{4}$, and concentrated under reduced pressure. The Boc-protected 12a was dissolved in DCM $(5 \mathrm{~mL})$, trifluoroacetic acid $(5 \mathrm{~mL})$ was added. The reaction mixture was allowed to stir for $2 \mathrm{~h}$ at r.t. and concentrated under reduced pressure. The residue was purified by column chromatography over silica gel and further 
purified by recrystallization (ethyl ether) to obtain the title compound as a white solid (1.2 g, yield 64.8\%). ${ }^{1} \mathrm{H}$ NMR (600 MHz, DMSO- $\left.d_{6}\right) \delta: 10.42(1 \mathrm{H}, \mathrm{s})$, $8.34(3 \mathrm{H}, \mathrm{s}), 8.01-7.96(3 \mathrm{H}, \mathrm{m}), 7.70(1 \mathrm{H}, \mathrm{d}, J=8.4 \mathrm{~Hz}), 7.61(1 \mathrm{H}, \mathrm{t}, J=8.4$ $\mathrm{Hz}), 7.54(2 \mathrm{H}, \mathrm{t}, J=7.8 \mathrm{~Hz}), 7.41(1 \mathrm{H}, \mathrm{t}, J=7.8 \mathrm{~Hz}), 7.22(1 \mathrm{H}, \mathrm{d}, J=7.8 \mathrm{~Hz})$, $4.04(2 \mathrm{H}, \mathrm{s}) .{ }^{13} \mathrm{C}$ NMR (150 MHz, DMSO- $\left.d_{6}\right) \delta: 166.1,139.9,135.2,134.9$, $132.1,129.4,128.8,128.1,124.4,121.3,121.0,42.9$.

\subsubsection{N-[3-(Aminomethyl)pheny] cinnamamide (12b)}

Compound 12b was prepared following a similar procedure to compound 12a. Yield: $53.5 \% .{ }^{1} \mathrm{H}$ NMR $\left(600 \mathrm{MHz}, \mathrm{DMSO}-d_{6}\right) \delta: 10.24(1 \mathrm{H}, \mathrm{s}), 7.67(1 \mathrm{H}$, s), 7.65-7.54 (4H, m), 7.49-7.38 (3H, m), $7.28(1 \mathrm{H}, \mathrm{t}, J=8.0 \mathrm{~Hz}), 7.08(1 \mathrm{H}, \mathrm{d}, J$ $=8.0 \mathrm{~Hz}), 6.88(1 \mathrm{H}, \mathrm{d}, J=16 \mathrm{~Hz}), 3.76(2 \mathrm{H}, \mathrm{s}) .{ }^{13} \mathrm{C}$ NMR $\left(150 \mathrm{MHz}, \mathrm{DMSO}-d_{6}\right)$ $\delta: 163.9,143.6,140.4,139.6,135.2,130.2,129.4,129.1,128.2,122.9,122.8$, 118.6, 118.1, 45.6 .

\subsubsection{N-[3-(Aminomethyl)phenyl]-3-phenylpropanamide (12c)}

Compound 12c was prepared following a similar procedure to compound 12a. Yield: $66.8 \% .{ }^{1} \mathrm{H}$ NMR (600 MHz, DMSO- $\left.d_{6}\right) \delta: 10.08(1 \mathrm{H}, \mathrm{s}), 8.25(3 \mathrm{H}$, s), $7.78(1 \mathrm{H}, \mathrm{s}), 7.48(1 \mathrm{H}, \mathrm{d}, J=8.4 \mathrm{~Hz}), 7.34(1 \mathrm{H}, \mathrm{t}, J=8.4 \mathrm{~Hz}), 7.32-7.24(4 \mathrm{H}$, m), $7.18(1 \mathrm{H}, \mathrm{t}, J=7.2 \mathrm{~Hz}), 7.13(1 \mathrm{H}, \mathrm{d}, J=7.8 \mathrm{~Hz}), 3.99(2 \mathrm{H}, \mathrm{q}, J=6.0 \mathrm{~Hz})$, $2.91(2 \mathrm{H}, \mathrm{t}, J=7.8 \mathrm{~Hz}), 2.65(2 \mathrm{H}, \mathrm{t}, J=7.8 \mathrm{~Hz}) .{ }^{13} \mathrm{C}$ NMR $\left(150 \mathrm{MHz}, \mathrm{DMSO}-d_{6}\right)$ $\delta: 171.0,141.5,139.9,134.9,129.5,128.7,128.6,126.4,123.8,120.0,119.6$, $42.9,38.2,31.2$. 
4.4.4. Benzo[b]thiophene-2-carboxylic acid 3-benzoylamino-benzylamide (13a)

The solution of EDCI (107 mg, $0.56 \mathrm{mmol})$ and DMAP (3 mg, $0.03 \mathrm{mmol})$ in $5 \mathrm{~mL}$ DCM was added dropwise to a mixture of compound 12a (69 $\mathrm{mg}, 0.31$ mmol) and benzo[b]thiophene-2-carboxylic acid (50 $\mathrm{mg}, 0.28 \mathrm{mmol})$ in $5 \mathrm{~mL}$ DCM at $0{ }^{\circ} \mathrm{C}$ under nitrogen atmosphere, and the mixture was warmed to r.t. and stirred overnight. The mixture was quenched with water and extracted with DCM. The organic layer was washed with $1 \mathrm{M} \mathrm{NaOH}(20 \mathrm{~mL}), 1 \mathrm{M} \mathrm{HCl}(20$ $\mathrm{mL})$, and saturated $\mathrm{NaHCO}_{3}(10 \mathrm{~mL})$, dried over $\mathrm{Na}_{2} \mathrm{SO}_{4}$, and concentrated under reduced pressure. The residue was purified by column chromatography over silica gel and further purified by recrystallization (ethyl ether) to obtain the title compound as a white solid (45 mg, yield $41.5 \%$ ) Mp: $258-260{ }^{\circ} \mathrm{C} .{ }^{1} \mathrm{H}$ NMR $\left(400 \mathrm{MHz}, \mathrm{DMSO}-d_{6}\right) \delta: 10.31(1 \mathrm{H}, \mathrm{s}), 9.43(1 \mathrm{H}, \mathrm{t}, J=6.0 \mathrm{~Hz}), 8.20(1 \mathrm{H}, \mathrm{s})$, $8.02(1 \mathrm{H}, \mathrm{d}, J=7.2 \mathrm{~Hz}), 7.99-7.91(3 \mathrm{H}, \mathrm{m}), 7.79(1 \mathrm{H}, \mathrm{s}), 7.73(1 \mathrm{H}, \mathrm{d}, J=8.0$ $\mathrm{Hz}), 7.56(1 \mathrm{H}, \mathrm{m}), 7.55-7.41(4 \mathrm{H}, \mathrm{m}), 7.33(1 \mathrm{H}, \mathrm{t}, J=8.0 \mathrm{~Hz}), 7.10(1 \mathrm{H}, \mathrm{d}, J=$ $7.2 \mathrm{~Hz}), 4.51(2 \mathrm{H}, \mathrm{d}, J=6.0 \mathrm{~Hz}) .{ }^{13} \mathrm{C}$ NMR $\left(100 \mathrm{MHz}, \mathrm{DMSO}-d_{6}\right) \delta: 166.1$, $161.9,140.6,140.4,140.2,139.7,139.6,135.3,131.9,129.0,128.8,128.1$, 126.6, 125.6, 125.3, 123.3, 123.2, 119.7, 119.5, 43.2. HRMS calcd for $\mathrm{C}_{23} \mathrm{H}_{19} \mathrm{~N}_{2} \mathrm{O}_{2} \mathrm{~S}(\mathrm{M}+\mathrm{H})^{+}$387.1167, found 387.1164. HPLC purity: $97.4 \%$ (14.0 $\min )$.

4.4.5. 4'-Bromo-biphenyl-3-carboxylic acid 3-benzoylamino-benzylamide 
$(13 b)$

Compound 13b was prepared following a similar procedure to compound 13a. Yield: $37.5 \%$. Mp: $253-256{ }^{\circ} \mathrm{C} .{ }^{1} \mathrm{H}$ NMR (600 MHz, DMSO- $\left.d_{6}\right) \delta: 10.27(1 \mathrm{H}, \mathrm{s})$, $9.22(1 \mathrm{H}, \mathrm{t}, J=6.0 \mathrm{~Hz}), 8.22(1 \mathrm{H}, \mathrm{s}), 7.94(3 \mathrm{H}, \mathrm{m}), 7.85(1 \mathrm{H}, \mathrm{d}, J=7.8 \mathrm{~Hz})$, $7.78(1 \mathrm{H}, \mathrm{s}), 7.75-7.65(5 \mathrm{H}, \mathrm{m}), 7.62-7.55(2 \mathrm{H}, \mathrm{m}), 7.51(1 \mathrm{H}, \mathrm{t}, J=7.8 \mathrm{~Hz})$, $7.32(1 \mathrm{H}, \mathrm{t}, J=7.8 \mathrm{~Hz}), 7.10(1 \mathrm{H}, \mathrm{d}, J=7.8 \mathrm{~Hz}), 4.54(2 \mathrm{H}, \mathrm{d}, J=6.0 \mathrm{~Hz}) .{ }^{13} \mathrm{C}$ NMR (150 MHz, DMSO-d $\left.d_{6}\right) \delta: 166.4,166.0,140.6,139.7,139.4,139.4,135.6$, $135.4,132.3,132.0,129.8,129.6,129.4,129.0,128.8,128.1,127.4,125.7$, 123.1, 121.8, 119.5, 119.3, 43.2. HRMS calcd for $\mathrm{C}_{27} \mathrm{H}_{22} \mathrm{~N}_{2} \mathrm{O}_{2} \mathrm{Br}(\mathrm{M}+\mathrm{H})^{+}$ 485.0865, found 385.0861. HPLC purity: 95.7\% (15.7 min).

4.4.6. 4'-Bromo-biphenyl-3-carboxylic acid 3-(3-phenyl-acryloylamino)benzylamide $(\mathbf{1 3 c})$

The solution of EDCI (107 mg, $0.56 \mathrm{mmol})$ and DMAP (3 mg, $0.03 \mathrm{mmol})$ in $5 \mathrm{~mL}$ dichloromethane was added dropwise to a mixture of compound $\mathbf{1 2 b}$ (78 $\mathrm{mg}, 0.31 \mathrm{mmol}$ ) and 4'-bromo-biphenyl-3-carboxylic acid (50 mg, 0.18 mmol) in $5 \mathrm{~mL} \mathrm{DCM}$ at $0{ }^{\circ} \mathrm{C}$ under nitrogen atmosphere, and the mixture was warmed to r.t. and stirred overnight. After quenched with water and extracted with DCM, the organic layer was washed with $1 \mathrm{M} \mathrm{NaOH}(20 \mathrm{~mL}), 1 \mathrm{M} \mathrm{HCl}$ (20 mL), and saturated $\mathrm{NaHCO}_{3}(10 \mathrm{~mL})$, dried over $\mathrm{Na}_{2} \mathrm{SO}_{4}$, and concentrated under reduced pressure. The residue was purified by column chromatography over silica gel and further purified by recrystallization (ethyl ether) to obtain the title compound as a white solid (43 mg, yield 30.3\%). Mp: $236-238{ }^{\circ} \mathrm{C} .{ }^{1} \mathrm{H}$ 
NMR $\left(400 \mathrm{MHz}, \mathrm{DMSO}-d_{6}\right) \delta: 10.21(1 \mathrm{H}, \mathrm{s}), 9.23(1 \mathrm{H}, \mathrm{t}, J=6.0 \mathrm{~Hz}), 8.23(1 \mathrm{H}$, s), $7.99(1 \mathrm{H}, \mathrm{s}), 7.95(1 \mathrm{H}, \mathrm{d}, J=8.0 \mathrm{~Hz}), 7.89(1 \mathrm{H}, \mathrm{d}, J=8.0 \mathrm{~Hz}), 7.78(1 \mathrm{H}, \mathrm{d}, \mathrm{J}$ $=7.6 \mathrm{~Hz}), 7.71-7.53(7 \mathrm{H}, \mathrm{m}), 7.51-7.38(4 \mathrm{H}, \mathrm{m}), 7.31(1 \mathrm{H}, \mathrm{t}, J=7.6 \mathrm{~Hz}), 7.07$ $(1 \mathrm{H}, \mathrm{d}, J=7.6 \mathrm{~Hz}), 6.83(1 \mathrm{H}, \mathrm{d}, J=15.6 \mathrm{~Hz}), 4.54(2 \mathrm{H}, \mathrm{d}, J=6.0 \mathrm{~Hz}) .{ }^{13} \mathrm{C}$ NMR (100 MHz, DMSO- $\left.d_{6}\right) \delta: 166.4,163.9,140.8,140.6,139.8,139.4,139.4$, $135.5,135.2,132.3,132.0,130.3,129.8,129.7,129.5,129.4,129.2,128.2$, 127.4, 125.7, 122.8, 121.8, 118.2, 118.2, 43.1. HRMS calcd for $\mathrm{C}_{29} \mathrm{H}_{24} \mathrm{~N}_{2} \mathrm{O}_{2} \mathrm{Br}$ $(\mathrm{M}+\mathrm{H})^{+}$511.1021, found 511.1021.HPLC purity: 98.7\% (13.8 min).

\subsubsection{3'-Bromo-biphenyl-3-carboxylic acid 3-(3-phenyl-acryloylamino)-} benzylamide $(\mathbf{1 3 d})$

Compound 13d was prepared following a similar procedure to compound 13c. Yield: $47.4 \%$. Mp: $231-233{ }^{\circ} \mathrm{C} .{ }^{1} \mathrm{H}$ NMR (400 MHz, DMSO- $\left.d_{6}\right) \delta: 10.21$ $(1 \mathrm{H}, \mathrm{s}), 9.24(1 \mathrm{H}, \mathrm{t}, J=6.0 \mathrm{~Hz}), 8.24(1 \mathrm{H}, \mathrm{s}), 7.94(1 \mathrm{H}, \mathrm{d}, J=8.0 \mathrm{~Hz}), 7.86(1 \mathrm{H}$, $\mathrm{d}, J=8.0 \mathrm{~Hz}), 7.77-7.65(6 \mathrm{H}, \mathrm{m}), 7.64-7.57(4 \mathrm{H}, \mathrm{m}), 7.48-7.38(3 \mathrm{H}, \mathrm{m}), 7.31$ $(1 \mathrm{H}, \mathrm{t}, J=7.6 \mathrm{~Hz}), 7.07(1 \mathrm{H}, \mathrm{d}, J=7.6 \mathrm{~Hz}), 6.84(1 \mathrm{H}, \mathrm{d}, J=15.6 \mathrm{~Hz}), 4.54(2 \mathrm{H}$, $\mathrm{d}, J=6.0 \mathrm{~Hz}) .{ }^{13} \mathrm{C}$ NMR $\left(100 \mathrm{MHz}, \mathrm{DMSO}-d_{6}\right) \delta: 166.4,163.9,142.4,140.7$, $140.6,139.8,139.1,135.5,135.2,131.6,131.0,130.2,130.1,129.9,129.7$ $129.5,129.0,129.2,128.2,127.8,126.5,125.9,122.9,122.8,118.2,118.2,43.1$. HRMS calcd for $\mathrm{C}_{29} \mathrm{H}_{24} \mathrm{~N}_{2} \mathrm{O}_{2} \mathrm{Br}(\mathrm{M}+\mathrm{H})^{+}$511.1021, found 511.1026. HPLC purity: 97.4\% (15.1 min).

4.4.8. Biphenyl-3-carboxylic acid 3-(3-phenyl-acryloylamino)-benzylamide 
$(13 e)$

Compound 13e was prepared following a similar procedure to compound $\mathbf{1 3 c}$. Yield: $49.4 \%$. Mp: $191-193{ }^{\circ} \mathrm{C} .{ }^{1} \mathrm{H}$ NMR (400 MHz, DMSO- $\left.d_{6}\right) \delta: 10.21(1 \mathrm{H}, \mathrm{s})$, $9.23(1 \mathrm{H}, \mathrm{t}, J=6.0 \mathrm{~Hz}), 8.23(1 \mathrm{H}, \mathrm{s}), 7.92(1 \mathrm{H}, \mathrm{d}, J=8.0 \mathrm{~Hz}), 7.86(1 \mathrm{H}, \mathrm{d}, J=$ $7.6 \mathrm{~Hz}), 7.77(2 \mathrm{H}, \mathrm{d}, J=7.2 \mathrm{~Hz}), 7.68(1 \mathrm{H}, \mathrm{d}, J=8.0 \mathrm{~Hz}), 7.66-7.54(5 \mathrm{H}, \mathrm{m})$, $7.51(2 \mathrm{H}, \mathrm{t}, J=7.6 \mathrm{~Hz}), 7.48-7.38(4 \mathrm{H}, \mathrm{m}), 7.31(1 \mathrm{H}, \mathrm{t}, J=7.6 \mathrm{~Hz}), 7.06(1 \mathrm{H}, \mathrm{d}$, $J=7.6 \mathrm{~Hz}), 6.83(1 \mathrm{H}, \mathrm{d}, J=15.6 \mathrm{~Hz}), 4.53(2 \mathrm{H}, \mathrm{d}, J=6.0 \mathrm{~Hz}) \cdot{ }^{13} \mathrm{C}$ NMR $(100$ MHz, DMSO- $\left.d_{6}\right) \delta: 166.5,164.0,140.9,140.7,140.6,140.0,139.9,135.4$, $135.2,130.2,129.9,129.6,129.5,129.2,128.3,128.2,127.4,127.0,125.9$, 122.8, 118.3, 118.2, 43.1. HRMS calcd for $\mathrm{C}_{29} \mathrm{H}_{25} \mathrm{~N}_{2} \mathrm{O}_{2}(\mathrm{M}+\mathrm{H})^{+} 433.1916$, found 433.1914. HPLC purity: 98.1\% (15.0 min).

4.4.9. 4'-Methoxy-biphenyl-3-carboxylic acid 3-(3-phenyl-acryloylamino)benzylamide $(\mathbf{1 3 f})$

Compound $\mathbf{1 3 f}$ was prepared following a similar procedure to compound $\mathbf{1 3 c}$. Yield: 30.8\%. Mp: $195-197{ }^{\circ} \mathrm{C} .{ }^{1} \mathrm{H}$ NMR (400 MHz, DMSO- $\left.d_{6}\right) \delta: 10.22(1 \mathrm{H}, \mathrm{s})$, $9.21(1 \mathrm{H}, \mathrm{t}, J=6.0 \mathrm{~Hz}), 8.19(1 \mathrm{H}, \mathrm{s}), 7.86(1 \mathrm{H}, \mathrm{d}, J=7.6 \mathrm{~Hz}), 7.80(1 \mathrm{H}, \mathrm{d}, J=$ 8.0 Hz), 7.74-7.64 (4H, m), 7.64-7.52 (4H, m), 7.48-7.38 (3H, m), $7.31(1 \mathrm{H}, \mathrm{t}, J$ $=7.6 \mathrm{~Hz}), 7.09-7.04(3 \mathrm{H}, \mathrm{m}), 6.84(1 \mathrm{H}, \mathrm{d}, J=16 \mathrm{~Hz}), 4.53(2 \mathrm{H}, \mathrm{d}, J=6.0 \mathrm{~Hz})$, $3.81(3 \mathrm{H}, \mathrm{s}) .{ }^{13} \mathrm{C}$ NMR (100 MHz, DMSO- $\left.d_{6}\right) \delta: 166.6,163.9,159.6,140.8$, $140.5,140.3,139.8,135.3,135.1,132.3,130.2,129.4,129.3,129.2,128.4$ $128.1,126.2,125.3,122.7,118.2,114.8,55.6,43.1$. HRMS calcd for $\mathrm{C}_{30} \mathrm{H}_{27} \mathrm{~N}_{2} \mathrm{O}_{3}(\mathrm{M}+\mathrm{H})^{+}$463.2022, found 463.2021. HPLC purity: 99.1\% (15.4 
$\min )$.

4.4.10.3-Benzyloxy-N-[3-(3-phenyl-acryloylamino)-benzyl]-benzamide (13g)

Compound $13 \mathrm{~g}$ was prepared following a similar procedure to compound $\mathbf{1 3 c}$. Yield: $22.1 \%$. Mp: $206-208{ }^{\circ} \mathrm{C} .{ }^{1} \mathrm{H}$ NMR (400 MHz, DMSO- $\left.d_{6}\right) \delta: 10.22(1 \mathrm{H}, \mathrm{s})$, $9.07(1 \mathrm{H}, \mathrm{t}, J=6.0 \mathrm{~Hz}), 7.66(1 \mathrm{H}, \mathrm{d}, J=8.0 \mathrm{~Hz}), 7.64-7.54(5 \mathrm{H}, \mathrm{m}), 7.52(1 \mathrm{H}, \mathrm{d}$, $J=8.0 \mathrm{~Hz}), 7.50-7.38(8 \mathrm{H}, \mathrm{m}), 7.37-7.27(2 \mathrm{H}, \mathrm{m}), 7.19(1 \mathrm{H}, \mathrm{dd}, J=8.0,2.0$ Hz), $7.03(1 \mathrm{H}, \mathrm{d}, J=8.0 \mathrm{~Hz}), 6.84(1 \mathrm{H}, \mathrm{d}, J=15.6 \mathrm{~Hz}), 5.17(2 \mathrm{H}, \mathrm{s}), 4.48(2 \mathrm{H}$, d, $J=6.0 \mathrm{~Hz}) .{ }^{13} \mathrm{C}$ NMR $\left(100 \mathrm{MHz}, \mathrm{DMSO}-d_{6}\right) \delta: 166.4,164.0,159.8,140.8$, $140.5,139.8,137.3,136.3,135.2,130.2,129.9,129.5,129.1,128.9,128.3$, 128.1, 122.8, 122.7, 120.3, 118.4, 118.3, 118.2, 114.1, 69.9, 43.1. HRMS calcd for $\mathrm{C}_{30} \mathrm{H}_{27} \mathrm{~N}_{2} \mathrm{O}_{3}(\mathrm{M}+\mathrm{H})^{+} 463.2022$, found 463.2021. HPLC purity: 99.5\% (15.4 $\min )$.

\subsubsection{N-(3-Cinnamamidobenzyl)-2-naphthamide (13h)}

Compound $\mathbf{1 3 h}$ was prepared following a similar procedure to compound $\mathbf{1 3 c}$. Yield: $25.9 \%$. Mp: $215-216{ }^{\circ} \mathrm{C} .{ }^{1} \mathrm{H}$ NMR (400 MHz, DMSO- $\left.d_{6}\right) \delta: 10.21(1 \mathrm{H}, \mathrm{s})$, $9.25(1 \mathrm{H}, \mathrm{t}, J=6.0 \mathrm{~Hz}), 8.54(1 \mathrm{H}, \mathrm{s}), 8.07-7.98(4 \mathrm{H}, \mathrm{m}), 7.68(1 \mathrm{H}, \mathrm{d}, J=8.0$ Hz), $7.65(1 \mathrm{H}, \mathrm{s}), 7.64-7.54(5 \mathrm{H}, \mathrm{m}), 7.48-7.38(3 \mathrm{H}, \mathrm{m}), 7.31(1 \mathrm{H}, \mathrm{t}, J=7.6 \mathrm{~Hz})$, $7.09(1 \mathrm{H}, \mathrm{d}, J=7.6 \mathrm{~Hz}), 6.83(1 \mathrm{H}, \mathrm{d}, J=15.6 \mathrm{~Hz}), 4.55(2 \mathrm{H}, \mathrm{d}, J=6.0 \mathrm{~Hz})$. ${ }^{13} \mathrm{C}$ NMR (100 MHz, DMSO- $\left.d_{6}\right) \delta: 166.7,163.9,140.8,140.5,139.8,135.2$, $134.6,132.6,130.2,129.5,129.3,129.2,128.4,128.2,128.1,128.0,127.2$, 124.6, 122.8, 122.7, 118.3, 118.2, 43.2. HRMS calcd for $\mathrm{C}_{27} \mathrm{H}_{23} \mathrm{~N}_{2} \mathrm{O}_{2}(\mathrm{M}+\mathrm{H})^{+}$ 
407.1760, found 407.1764. HPLC purity: 98.5\% (14.8 min).

\subsubsection{2. (E)-N-(3-Cinnamamidobenzyl)-1-naphthamide (13i)}

Compound $13 \mathbf{i}$ was prepared following a similar procedure to compound $\mathbf{1 3 c}$. Yield: $26.7 \%$. Mp: $210-212{ }^{\circ} \mathrm{C} .{ }^{1} \mathrm{H}$ NMR (400 MHz, DMSO- $\left.d_{6}\right) \delta: 10.26(1 \mathrm{H}, \mathrm{s})$, $9.12(1 \mathrm{H}, \mathrm{t}, J=6.0 \mathrm{~Hz}), 8.26(1 \mathrm{H}, \mathrm{m}), 8.04(1 \mathrm{H}, \mathrm{d}, J=8.4 \mathrm{~Hz}), 7.98(1 \mathrm{H}$, m), 7.77 (1H, s), 7.73-7.54 (8H, m), 7.48-7.38 (3H, m), $7.34(1 \mathrm{H}, \mathrm{t}, J=7.6 \mathrm{~Hz})$, $7.12(1 \mathrm{H}, \mathrm{d}, J=7.6 \mathrm{~Hz}), 6.87(1 \mathrm{H}, \mathrm{d}, J=15.6 \mathrm{~Hz}), 4.55(2 \mathrm{H}, \mathrm{d}, J=6.0 \mathrm{~Hz})$. ${ }^{13} \mathrm{C}$ NMR (100 MHz, DMSO- $\left.d_{6}\right) \delta: 169.1,164.0,140.8,140.6,139.9,135.2$, $135.1,133.6,130.3,130.3,130.3,129.5,129.3,128.7,128.2,127.2,126.7$, 125.9, 125.7, 125.5, 122.8, 118.4, 118.2, 43.0. HRMS calcd for $\mathrm{C}_{27} \mathrm{H}_{23} \mathrm{~N}_{2} \mathrm{O}_{2}$ $(\mathrm{M}+\mathrm{H})^{+}$407.1760, found 407.1763. HPLC purity: 95.9\% (14.8 min).

\subsubsection{Benzo[b]thiophene-2-carboxylic acid 3-(3-phenyl-acryloylamino)-} benzylamide (13j)

Compound $\mathbf{1 3 \mathbf { j }}$ was prepared following a similar procedure to compound $\mathbf{1 3 \mathbf { c }}$. Yield: 34.6\%. Mp: $163-165{ }^{\circ} \mathrm{C} .{ }^{1} \mathrm{H}$ NMR (400 MHz, DMSO- $\left.d_{6}\right) \delta: 10.24(1 \mathrm{H}, \mathrm{s})$, $9.37(1 \mathrm{H}, \mathrm{t}, J=6.0 \mathrm{~Hz}), 8.17(1 \mathrm{H}, \mathrm{s}), 8.04(1 \mathrm{H}, \mathrm{d}, J=7.2 \mathrm{~Hz}), 7.96(1 \mathrm{H}, \mathrm{dd}, J=$ 6.4, $2.0 \mathrm{~Hz}), 7.68(1 \mathrm{H}, \mathrm{d}, J=8.0 \mathrm{~Hz}), 7.65(1 \mathrm{H}, \mathrm{s}), 7.63-7.54(3 \mathrm{H}, \mathrm{m}), 7.51-7.38$ $(5 \mathrm{H}, \mathrm{m}), 7.32(1 \mathrm{H}, \mathrm{t}, J=7.6 \mathrm{~Hz}), 7.06(1 \mathrm{H}, \mathrm{d}, J=7.6 \mathrm{~Hz}), 6.84(1 \mathrm{H}, \mathrm{d}, J=15.6$ $\mathrm{Hz}), 4.50(2 \mathrm{H}, \mathrm{d}, J=6.0 \mathrm{~Hz}) .{ }^{13} \mathrm{C}$ NMR $\left(100 \mathrm{MHz}, \mathrm{DMSO}-d_{6}\right) \delta: 164.0,162.0$, $140.7,140.6,140.4,140.3,139.9,139.6,135.2,130.2,129.4,129.3,128.2$, 126.7, 125.6, 125.4, 125.3, 123.3, 122.9, 122.8, 118.4, 118.3, 43.2. HRMS calcd 
for $\mathrm{C}_{25} \mathrm{H}_{21} \mathrm{~N}_{2} \mathrm{O}_{2} \mathrm{~S}(\mathrm{M}+\mathrm{H})^{+} 413.1324$, found 413.1324. HPLC purity: 99.5\% (14.5 $\min )$.

4.4.14. 4'-Bromo-biphenyl-3-carboxylic acid 3-(3-phenyl-propionylamino)benzylamide (13k)

Compound 13k was prepared following a similar procedure to compound $\mathbf{1 3 c}$. Yield: 37.2\%. Mp: $191-193{ }^{\circ} \mathrm{C} .{ }^{1} \mathrm{H}$ NMR (400 MHz, DMSO-d $\left.d_{6}\right) \delta: 9.90(1 \mathrm{H}, \mathrm{s})$, $9.19(1 \mathrm{H}, \mathrm{t}, J=6.0 \mathrm{~Hz}), 8.21(1 \mathrm{H}, \mathrm{s}), 7.92(1 \mathrm{H}, \mathrm{d}, J=7.6 \mathrm{~Hz}), 7.86(1 \mathrm{H}, \mathrm{d}, J=$ $8.0 \mathrm{~Hz}), 7.73(2 \mathrm{H}, \mathrm{d}, J=8.4 \mathrm{~Hz}), 7.69(2 \mathrm{H}, \mathrm{d}, J=8.4 \mathrm{~Hz}), 7.59(1 \mathrm{H}, \mathrm{t}, J=8.0$ $\mathrm{Hz}), 7.52(2 \mathrm{H}, \mathrm{d}, J=7.2 \mathrm{~Hz}), 7.29-7.22(5 \mathrm{H}, \mathrm{m}), 7.16(1 \mathrm{H}, \mathrm{t}, J=7.2 \mathrm{~Hz}), 7.01$ $(1 \mathrm{H}, \mathrm{d}, J=7.2 \mathrm{~Hz}), 4.49(2 \mathrm{H}, \mathrm{d}, J=6.0 \mathrm{~Hz}), 2.89(2 \mathrm{H}, \mathrm{t}, J=7.2 \mathrm{~Hz}), 2.60(2 \mathrm{H}$, $\mathrm{t}, J=7.2 \mathrm{~Hz}) .{ }^{13} \mathrm{C}$ NMR (100 MHz, DMSO- $\left.d_{6}\right) \delta: 170.8,166.4,141.7,140.6$, $139.8,139.2,135.5,132.4,129.8,129.7,129.4,129.1,128.8,128.7,127.4$, $126.4,125.7,122.4,121.8,118.2,118.0,43.1,38.4,31.3$. HRMS calcd for $\mathrm{C}_{29} \mathrm{H}_{26} \mathrm{BrN}_{2} \mathrm{O}_{2}(\mathrm{M}+\mathrm{H})^{+}$513.1178, found 513.1174. HPLC purity: 99.2\% (15.6 $\min )$.

4.4.15. Biphenyl-3-carboxylic acid 3-(3-phenyl-propionylamino)-benzylamide (13l)

Compound $\mathbf{1 3 l}$ was prepared following a similar procedure to compound 13k. Yield: $30.1 \%$. Mp: $159-161{ }^{\circ} \mathrm{C} .{ }^{1} \mathrm{H}$ NMR (400 MHz, DMSO- $\left.d_{6}\right) \delta: 9.9(1 \mathrm{H}, \mathrm{s})$, $9.18(1 \mathrm{H}, \mathrm{t}, J=6.0 \mathrm{~Hz}), 8.21(1 \mathrm{H}, \mathrm{s}), 7.9(1 \mathrm{H}, \mathrm{d}, J=8.0 \mathrm{~Hz}), 7.85(1 \mathrm{H}, \mathrm{d}, J=$ $8.0 \mathrm{~Hz}), 7.76(2 \mathrm{H}, \mathrm{d}, J=7.2 \mathrm{~Hz}), 7.58(1 \mathrm{H}, \mathrm{t}, J=8.0 \mathrm{~Hz}), 7.55-7.48(4 \mathrm{H}, \mathrm{m})$, 
$7.41(1 \mathrm{H}, \mathrm{t}, J=7.6 \mathrm{~Hz}), 7.3-7.21(5 \mathrm{H}, \mathrm{m}), 7.16(1 \mathrm{H}, \mathrm{td}, J=7.6,1.6 \mathrm{~Hz}), 7.01$ $(1 \mathrm{H}, \mathrm{d}, J=7.6 \mathrm{~Hz}), 4.49(2 \mathrm{H}, \mathrm{d}, J=6.0 \mathrm{~Hz}) .2 .89(2 \mathrm{H}, \mathrm{t}, J=7.6 \mathrm{~Hz}), 2.60(2 \mathrm{H}$, t, $J=7.6 \mathrm{~Hz}) .{ }^{13} \mathrm{C}$ NMR $\left(100 \mathrm{MHz}, \mathrm{DMSO}-d_{6}\right) \delta: 166.7,163.9,140.8,140.6$, $139.8,135.1,134.6,132.6,130.2,129.5,129.3,129.2,128.4,128.2,128.1$, $128.0,127.2,124.6,122.8,122.7,118.3,118.2,43.2$. HRMS calcd for $\mathrm{C}_{29} \mathrm{H}_{27} \mathrm{~N}_{2} \mathrm{O}_{2}(\mathrm{M}+\mathrm{H})^{+}$435.2073, found 435.2069. HPLC purity: 97.3\% (15.3 $\min )$.

4.4.16.

4'-Methoxy-biphenyl-3-carboxylic

acid

3-(3-phenyl-propionylamino)-benzylamide (13m)

Compound 13m was prepared following a similar procedure to compound 13c. Yield: $37.2 \%$. Mp: $195-197{ }^{\circ} \mathrm{C} .{ }^{1} \mathrm{H}$ NMR (400 MHz, DMSO- $\left.d_{6}\right) \delta: 9.90$ $(1 \mathrm{H}, \mathrm{s}), 9.16(1 \mathrm{H}, \mathrm{t}, J=5.6 \mathrm{~Hz}), 8.16(1 \mathrm{H}, \mathrm{s}), 7.84(1 \mathrm{H}, \mathrm{d}, J=7.2 \mathrm{~Hz}), 7.80(1 \mathrm{H}$, $\mathrm{d}, J=7.6 \mathrm{~Hz}), 7.70(2 \mathrm{H}, \mathrm{d}, J=8.4 \mathrm{~Hz}), 7.56-7.52(3 \mathrm{H}, \mathrm{m}), 7.29-7.23(5 \mathrm{H}, \mathrm{m})$, 7.16(1H, s), $7.10(2 \mathrm{H}, \mathrm{d}, J=8.4 \mathrm{~Hz}), 7.01(1 \mathrm{H}, \mathrm{d}, J=7.2 \mathrm{~Hz}), 4.48(2 \mathrm{H}, \mathrm{d}, J=$ $5.6 \mathrm{~Hz}), 3.81(3 \mathrm{H}, \mathrm{s}), 2.89(2 \mathrm{H}, \mathrm{t}, J=8.0 \mathrm{~Hz}), 2.60(2 \mathrm{H}, \mathrm{t}, J=8.0 \mathrm{~Hz}) .{ }^{13} \mathrm{C}$ NMR (100 MHz, DMSO-d $)$ ): 170.8, 166.6, 159.6, 141.7, 140.7, 139.8, 135.4, $132.4,129.4,129.4,129.1,128.8,128.7,128.5,126.4,126.3,125.3,122.4$, 118.2, 118.0, 114.9, 55.7, 43.1, 38.4, 31.3. HRMS calcd for $\mathrm{C}_{30} \mathrm{H}_{29} \mathrm{~N}_{2} \mathrm{O}_{3}(\mathrm{M}+\mathrm{H})^{+}$ 465.2178, found 465.2177. HPLC purity: 99.2\% (15.6 min).

4.4.17. 3-Benzyloxy-N-[3-(3-phenyl-propionylamino)-benzyl]-benzamide (13n)

Compound 13n was prepared following a similar procedure to compound 13c. 
Yield: $24.7 \%$. Mp: $175-177{ }^{\circ} \mathrm{C} .{ }^{1} \mathrm{H}$ NMR (400 MHz, DMSO- $\left.d_{6}\right) \delta: 9.88(1 \mathrm{H}, \mathrm{s})$, $9.02(1 \mathrm{H}, \mathrm{t}, J=6.0 \mathrm{~Hz}), 7.55-7.54(1 \mathrm{H}, \mathrm{m}), 7.51-7.46(4 \mathrm{H}, \mathrm{m}), 7.45(1 \mathrm{H}, \mathrm{s})$, 7.41-7.36 (3H, m), 7.34-7.31 (1H, m), 7.27-7.20 (5H, m), 7.18-7.13 (2H, m), $6.96(1 \mathrm{H}, \mathrm{d}, J=8.0 \mathrm{~Hz}), 6.15(1 \mathrm{H}, \mathrm{s}), 4.42(2 \mathrm{H}, \mathrm{d}, J=6.0 \mathrm{~Hz}), 2.88(2 \mathrm{H}, \mathrm{t}, J=$ $7.6 \mathrm{~Hz}), 2.58(2 \mathrm{H}, \mathrm{t}, J=7.6 \mathrm{~Hz}) .{ }^{13} \mathrm{C}$ NMR $\left(100 \mathrm{MHz}, \mathrm{DMSO}-d_{6}\right) \delta: 170.8$, $166.3,158.8,141.7,140.7,139.8,137.4,136.3,130.0,129.1,128.9,128.8$, $128.7,128.4,128.2,126.4,122.4,120.2,118.3,118.2,118.0,114.0,69.9,43.1$, 38.4, 31.3. HRMS calcd for $\mathrm{C}_{30} \mathrm{H}_{29} \mathrm{~N}_{2} \mathrm{O}_{3}(\mathrm{M}+\mathrm{H})^{+}$465.2178, found 456.2181. HPLC purity: 96.3\% (15.1 min).

\section{Acknowledgements}

We thank National Science Foundation of China (81222042 and 81573264), the Ministry of Science and Technology of China (2012CB518001), the Young Teacher Start Plan of SJTU (14X100040051), and the E-Institutes of Shanghai Universities (EISU) Chemical Biology Division for financial support of this work. We thank Prof. Yingli Wu (SJTU) for his generous provision of plasmids of pET28a-SENP1, pET28a-RanGAP and pSAE1/SAE2-UBC9-SUMO1.

\section{References}

[1] S. Martin, K.A. Wilkinson, A. Nishimune, J.M. Henley, Emerging extranuclear roles of protein SUMOylation in neuronal function and dysfunction, Nat. Rev. Neurosci. 8 (2007) 948-959.

[2] P. Heun, SUMOrganization of the nucleus, Curr Opin Cell Biol. 19 (2007) 
$350-355$.

[3] R.J. Dohmen, SUMO protein modification, Biochim. Biophys. Acta. 1695 (2004) 113-131.

[4] E.S. Johnson, Protein modification by SUMO, Annu. Rev. Biochem. 73 (2004) 355-382.

[5] F. Melchior, M. Schergaut, A. Pichler, SUMO: ligases, isopeptidases and nuclear pores, Trends Biochem. Sci. 28 (2003) 612-618.

[6] J. Zhao, Sumoylation regulates diverse biological processes, Cell. Mol. Life Sci. 64 (2007) 3017-3033.

[7] R. Geiss-Friedlander F. Melchior, Concepts in sumoylation: a decade on, Nat. Rev. Mol. Cell Biol. 8 (2007) 947-956.

[8] R.T. Hay, SUMO-specific proteases: a twist in the tail, Trends Cell Biol. 17 (2007) 370-376.

[9] D. Mukhopadhyay M. Dasso, Modification in reverse: the SUMO proteases, Trends Biochem. Sci. 32 (2007) 286-295.

[10] J.H. Kim S.H. Baek, Emerging roles of desumoylating enzymes, Biochim. Biophys. Acta. 1792 (2009) 155-162.

[11] J. Cheng, T. Bawa, P. Lee, L. Gong, E.T. Yeh, Role of desumoylation in the development of prostate cancer, Neoplasia. 8 (2006) 667-676.

[12] T. Bawa-Khalfe, J. Cheng, S.H. Lin, M.M. Ittmann, E.T. Yeh, SENP1 induces prostatic intraepithelial neoplasia through multiple mechanisms, $\mathrm{J}$ Biol Chem. 285 (2010) 25859-25866. 
[13] Y. Zuo J.K. Cheng, Small ubiquitin-like modifier protein-specific protease 1 and prostate cancer, Asian J. Androl. 11 (2009) 36-38.

[14] Y. Xu, J. Li, Y. Zuo, J. Deng, L.S. Wang, G.Q. Chen, SUMO-specific protease 1 regulates the in vitro and in vivo growth of colon cancer cells with the upregulated expression of CDK inhibitors, Cancer Lett. 309 (2011) 78-84.

[15] J. Cheng, X. Kang, S. Zhang, E.T. Yeh, SUMO-specific protease 1 is essential for stabilization of HIF1alpha during hypoxia, Cell. 131 (2007) 584-595.

[16] Y. Xu, Y. Zuo, H. Zhang, X. Kang, F. Yue, Z. Yi, M. Liu, E.T. Yeh, G. Chen, J. Cheng, Induction of SENP1 in endothelial cells contributes to hypoxia-driven VEGF expression and angiogenesis, J. Biol. Chem. 285 (2010) 36682-36688.

[17] Z. Qiao, W. Wang, L. Wang, D. Wen, Y. Zhao, Q. Wang, Q. Meng, G. Chen, Y. Wu, H. Zhou, Design, synthesis, and biological evaluation of benzodiazepine-based SUMO-specific protease 1 inhibitors, Bioorg. Med. Chem. Lett. 21 (2011) 6389-6392.

[18] V.E. Albrow, E.L. Ponder, D. Fasci, M. Bekes, E. Deu, G.S. Salvesen, M. Bogyo, Development of small molecule inhibitors and probes of human SUMO deconjugating proteases, Chem. Biol. 18 (2011) 722-732.

[19] Y. Chen, D. Wen, Z. Huang, M. Huang, Y. Luo, B. Liu, H. Lu, Y. Wu, Y. Peng, J. Zhang, 2-(4-Chlorophenyl)-2-oxoethyl 4-benzamidobenzoate 
derivatives, a novel class of SENP1 inhibitors: Virtual screening, synthesis and biological evaluation, Bioorg. Med. Chem. Lett. 22 (2012) 6867-6870.

[20] I.G. Madu, A.T. Namanja, Y. Su, S. Wong, Y.J. Li, Y. Chen, Identification and characterization of a new chemotype of noncovalent SENP inhibitors, ACS Chem. Biol. 8 (2013) 1435-1441.

[21] L. Shen, M.H. Tatham, C. Dong, A. Zagorska, J.H. Naismith, R.T. Hay, SUMO protease SENP1 induces isomerization of the scissile peptide bond, Nat. Struct. Mol. Biol. 13 (2006) 1069-1077.

[22] L.N. Shen, C. Dong, H. Liu, J.H. Naismith, R.T. Hay, The structure of SENP1-SUMO-2 complex suggests a structural basis for discrimination between SUMO paralogues during processing, Biochem. J. 397 (2006) 279-288.

[23] Maestro, version 8.5, 2008, Schrödinger, LLC, New York, NY.

[24] G.A. Kaminski, R.A. Friesner, J. Tirado-Rives, W.L. Jorgensen, Evaluation and reparametrization of the OPLS-AA force field for proteins via comparison with accurate quantum chemical calculations on peptides, J. Phys. Chem. B. 105 (2001) 6474-6487.

[25] Glide, version 5.0, 2008, Schrodinger, LLC, New York, NY.

[26] LigPrep, version 2.2, 2005, Schrodinger, LLC, New York, NY. 
A

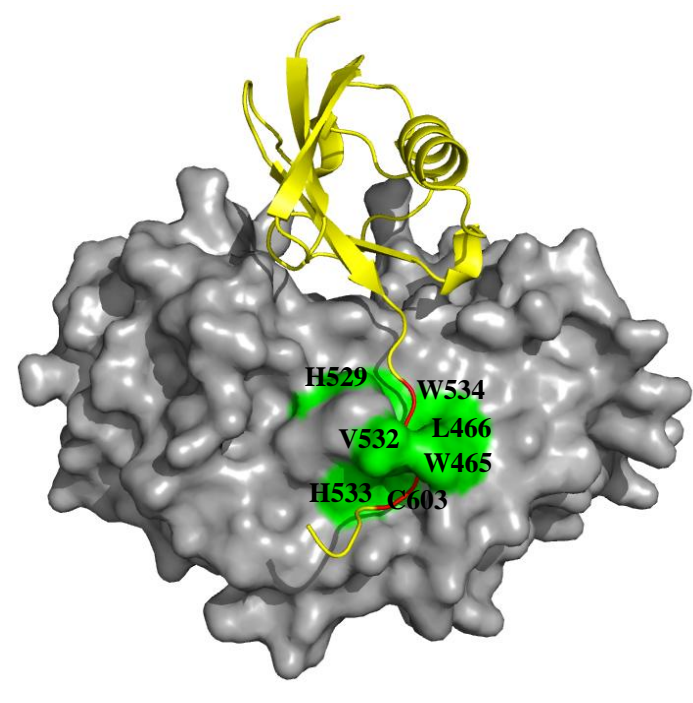

B

Specs Database

(197116)

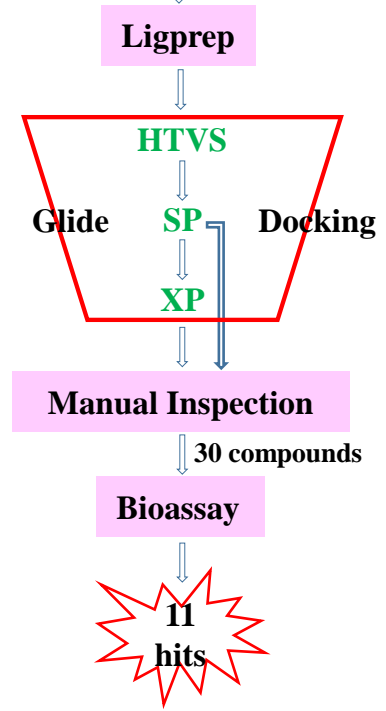

Figure 1. A, Complex of SENP1 (gray surface) and pre-SUMO (yellow cartoon) (PDB ID: 2IY1). The key residues of SENP1 are shown in green, the $\mathrm{T}^{90} \mathrm{GGH}^{93}$ peptide of pre-SUMO which is used for docking box definition is shown in red. B, Schematic representation of our hit discovery strategy.

Table 1. Inhibitory effect of hit compounds from in silico screening against SENP1. 


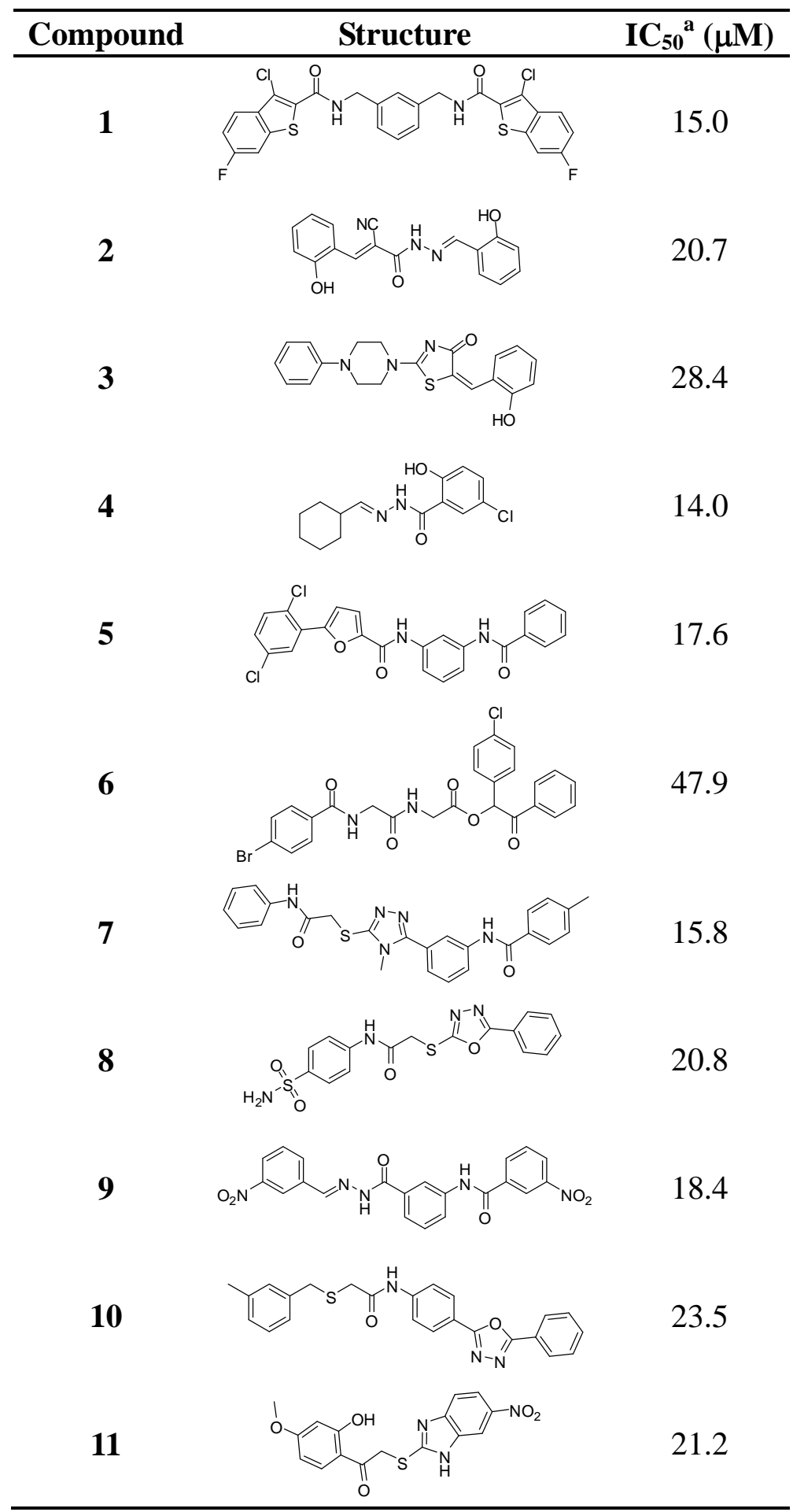

${ }^{\mathrm{a}} \mathrm{IC}_{50}$ measurement has an error range within $\pm 10 \%$. 
A

$A^{1}-L^{1} A^{2}-L^{2} A^{3}$ A: aromatic group

1

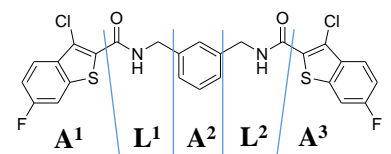

5

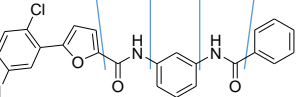

B

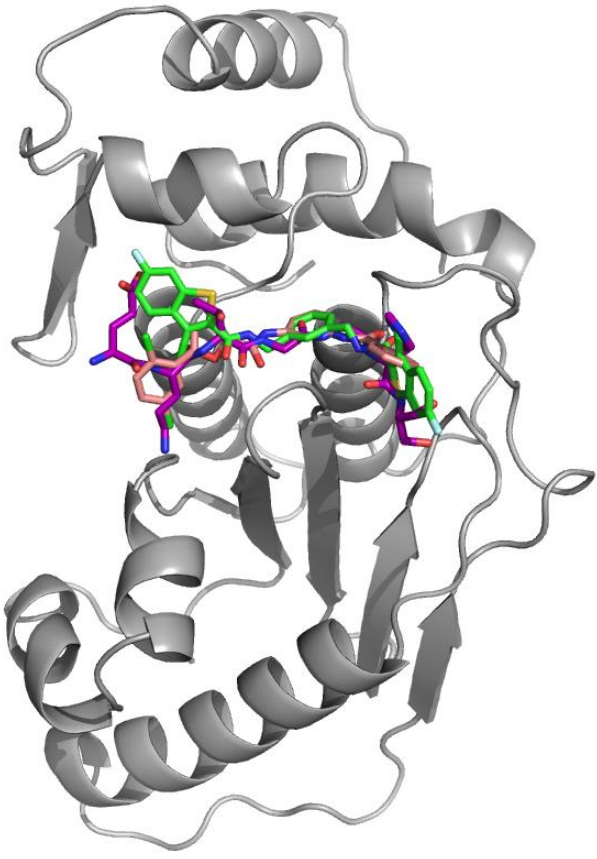

C

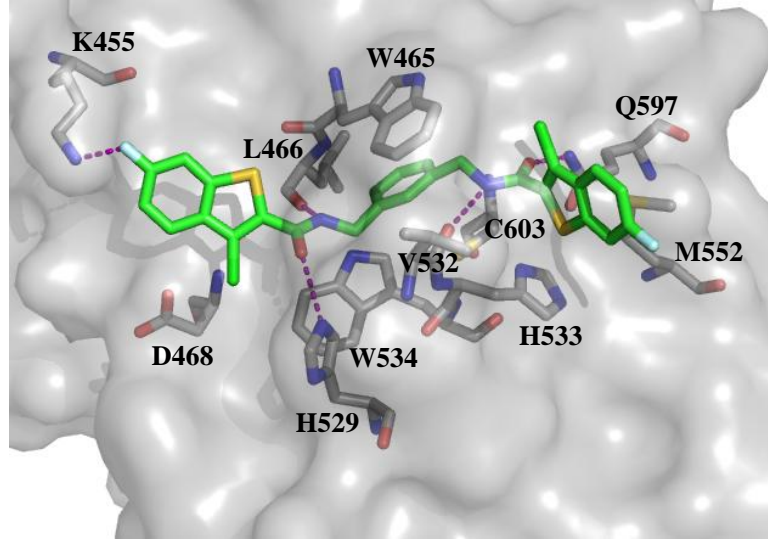

D

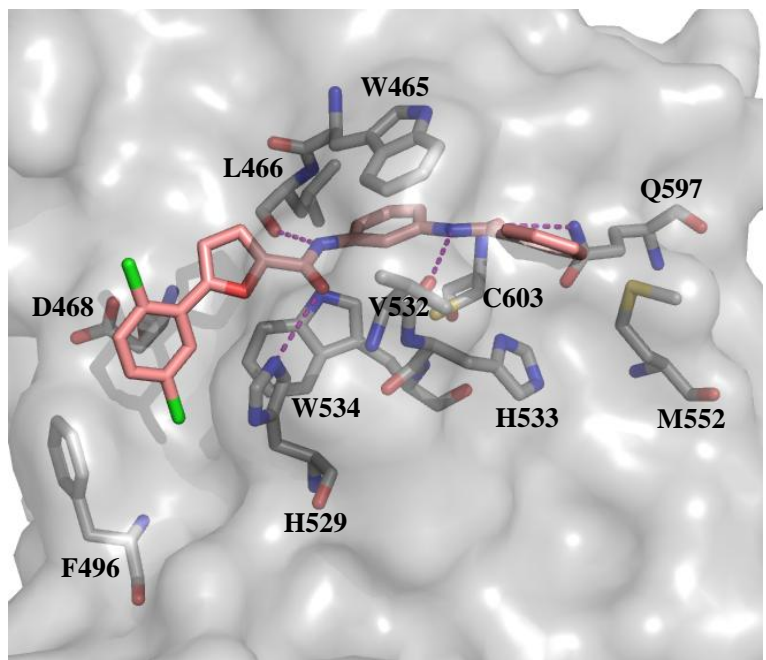

Figure 2. A, Representative structure of SENP1 inhibitors. B, Overlap of compounds $\mathbf{1}$ (green stick), $\mathbf{5}$ (salmon stick) and $\mathrm{E}^{88} \mathrm{QTGGHS}^{94}$ of pre-SUMO (purple stick) in SENP1 (gray cartoon) pocket. C, Detailed interactions between compound $\mathbf{1}$ and SENP1 (gray surface). D, Detailed interactions between compound $\mathbf{5}$ and SENP1 (gray surface). The residues interacting with compound $\mathbf{1}$ or $\mathbf{5}$ are shown in gray stick.

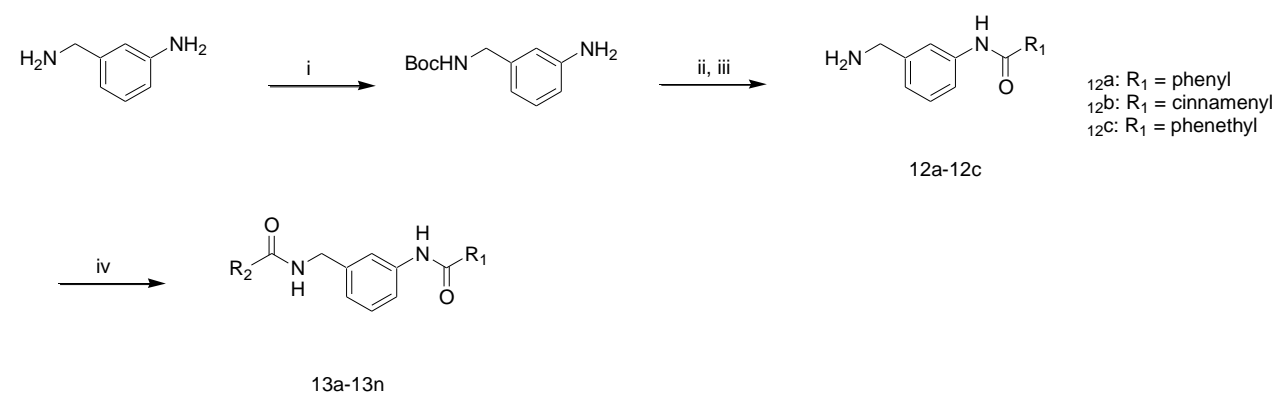

Scheme 1. Reagents and conditions: (i) $\mathrm{Boc}_{2} \mathrm{O}$, TEA, DCM, rt, $20 \mathrm{~h}$; (ii) $\mathrm{R}_{1} \mathrm{COOH}$, DCM, EDCI, DMAP, rt, overnight; (iii) TFA, DCM, rt, 2 h; (iv) $\mathrm{R}_{2} \mathrm{COOH}$, DCM, EDCI, DMAP, rt, overnight. 
Table 2. Inhibitory effect of designed compounds against SENP1.

(3)




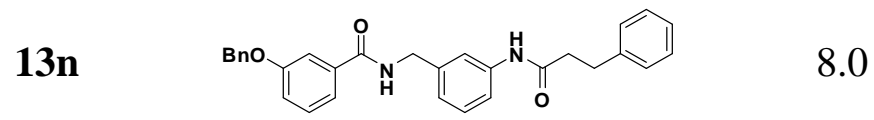

${ }^{\mathrm{a}} \mathrm{IC}_{50}$ measurement has an error range within $\pm 10 \%$.

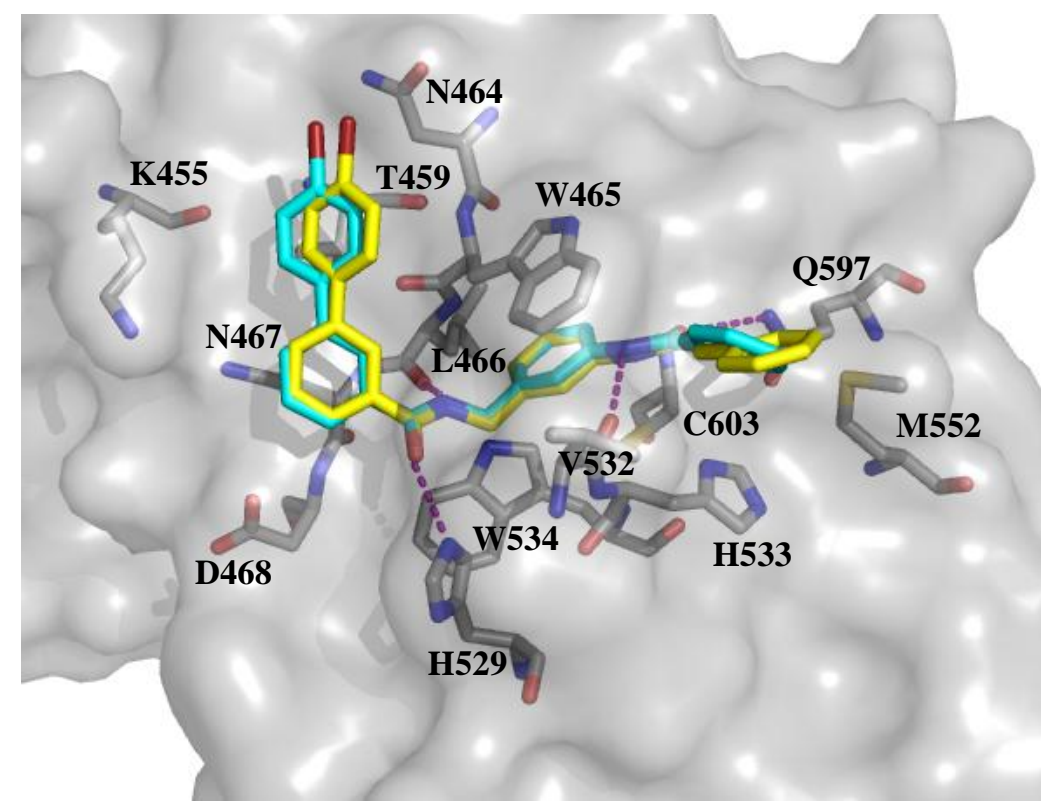

Figure 3. Overlap of compounds 13b (cyan stick) and 13c (yellow stick) in SENP1 (gray surface) pocket. The residues interacting with compounds $\mathbf{1 3 b}$ and $\mathbf{1 3 c}$ are shown in gray stick. 
Graphical abstract

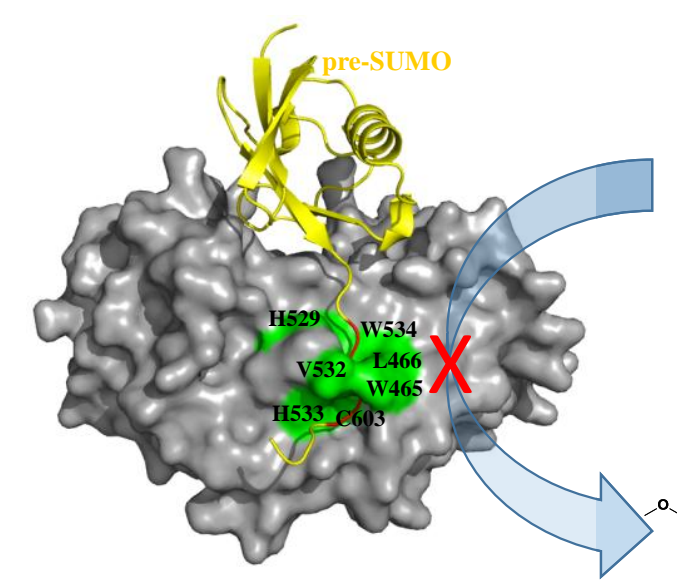

pre-SUMO in SENP1

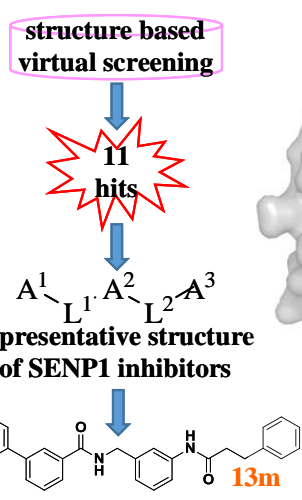

rational drug design

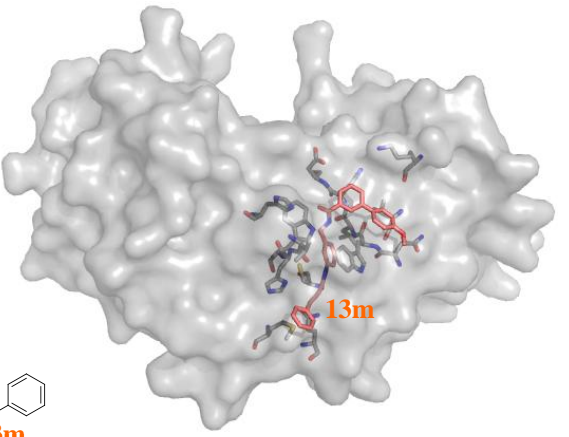

13m in SENP1 